\title{
Socio-Cultural Identities, Perceptions of Sexuality/Sexual Behavior and Cultural Contexts as Determinants of HIV and AIDS Prevalence in Southern Africa
}

\author{
Chijioke Uwah, Susan Wright
}

Tshwane University of Technology, Tshwane, South Africa.

Email: Chijiokeuwah@gmail.com

Received July $20^{\text {th }}, 2011$; revised October $29^{\text {th }}, 2011$; accepted November $14^{\text {th }}, 2011$

\begin{abstract}
This paper attempts to examine the connection between one's socio cultural setting and the prevalence of HIV/AIDS. Often, local communities form the contexts within which people negotiate their social and sexual lives and identities. These communities also play a key role in enabling or restraining people from taking control over their health. The paper will try to demonstrate through specific examples that in African societies, sexual behavior is a product of one's socio-cultural environment and structural contexts and not the cognitive properties of the individual. The article draws from the qualitative study (Focus group sessions, individual interviews) conducted in three high schools in the Boland area of the Western Cape with about 18 learners, 3 Life skills teachers, 3 Performer-Educators on the efficacy of the HIV/AIDS intervention by The Centre for HIV/AIDS Management theatre group based at the University of Stellenbosch. The aim of the study was to ascertain the cultural content of their campaign model as well as their knowledge of the determinants of sex and sexuality of their target areas. Based on the findings of this study, I argue that theatre will achieve greater success in its campaign against HIV/AIDS in South Africa if the designers of the campaign models adopt a more participatory approach, make indigenous culture central to the design of their intervention model and pay closer attention to what Campbell refers to as "community level of analysis" which simply put implies a greater understanding of the target audiences local communities and its determinants of sex and sexuality.
\end{abstract}

Keywords: Behavior; HIV/AIDS; Sexuality; Socio-Cultural Identity

\section{Introduction}

According to Hoeken and Swanepoel [1] the estimated prevalence rate of HIV and AIDS in South Africa is $10.8 \%$ - $11.2 \%$ i.e. 4.5 - 5.5 million of the general population, an estimated 2000 new infections daily and 800 HIV/AIDS related deaths per day. Campbell [2] postulates that the average life expectancy in Sub-Saharan Africa, which would have been 62 years without AIDS is now 47 years. In Botswana, it has dropped to 36, a level last seen in 1950. In Lesotho, people who turned 15 in 2000 have a 74\% percent chance of becoming infected before their $50^{\text {th }}$ birthday.

With all these statistics in mind, and with the knowledge that HIV/AIDS has caused indescribable suffering to millions of people, one wonders as Campbell [2] asks, why people knowingly engage in sexual behavior which could lead to a slow, painful, and premature death and why the best intentioned attempts to stem the tide of the HIV pandemic often have so little impact. In a paper re- viewing the factors promoting and perpetuating unsafe sexual behavior in South African youth, Eaton, Flisher and Aaro [3] reveal 50\% of young people as sexually active by the age of 16 . The majority of school students who had experienced sexual intercourse reported, at the most, one partner in the previous year, with a persistent minority of between $1 \%$ and $5 \%$ of females and $10 \%$ $25 \%$ of males having more than four partners per year. Additionally, $50 \%$ and $60 \%$ of sexually active youth report never using condoms. These scholars also ask the same question, "Why is it that the South African youth in the 1990's continue to practice unsafe sex (as evidenced by the spiraling rates of HIV infection), despite the concerted efforts of educational and HIV educational campaigns to influence their behavior?”

\section{Theoretical Framework}

The task of understanding the transmission and prevention of HIV and AIDS is one that has received much 
scholarly attention in a range of academic disciplines and levels of analysis. Campbell [2] describes two such levels of analysis; the micro-social level dominated by the opinions of health psychologists who have produced numerous academic papers linking sexual behavior to properties of the individual such as cognitive process instincts, attitudes, sense of personal vulnerability or perceived social norms and the macro social level, where economists, anthropologists and sociologists have drawn attention to the way factors such as poverty, gender inequality and global capitalism have shaped the contexts in which the pandemic flourishes. Campbell believes a key component of HIV and AIDS analysis has been overlooked namely how these micro and macro levels interact at local community level. In analysing the reasons for several failed intervention attempts, Perloff [4] remarks that one main reason for this lack of success is the complexity of the behaviour these interventions are trying to change. Studies have shown a poor understanding of sexuality and its contexts by many HIV and AIDS stakeholders may be responsible for the low success levels recorded against HIV and AIDS campaigns.

Campbell [2] believes many HIV prevention efforts in Sub-Saharan Africa have been dominated by the very biomedical and behavioral understandings of sexuality and health that allowed the epidemic to develop in the first place. It is important, she contends, that if prevention efforts are to have optimal impact, they need to be informed by sound insights into the determinants of sex and sexuality, yet these are the most mysterious and multi-faceted aspects of human behavior. According to her, early in the epidemic, it was assumed that sexual behavior was shaped by the conscious decisions of rational individuals. Locating the cause of sexual behavior at the individual level, she continues, led to individual behavioral interventions. Optimistic health promoters assumed that if only vulnerable people could be reached and educated about HIV and how to prevent it, they would quickly take care and safeguard themselves through changing their behavior. It is as simple as A.B.C. abstain, be faithful, and codomise. But studies have shown that many people knowingly engage in sexual behavior which puts their lives at risk. With full knowledge of the dangers of the epidemic, many people continue to have sex, often with multiple partners. Campbell is of the opinion that the forces shaping sexual behavior and sexual health are far more complex than individual rational decisions, based on simple factual knowledge about health risks and availability of medical services.

Recently, there has been a growing understanding that while sexuality cannot be divorced from the physical body, our instincts or emotions, it is socially constructed (Campbell [2]). Eaton, Flisher and Aaro [3] contend that factors which promote risk behaviours or create barriers to safer sex are structured along three domains of analysis: personal factors; the proximal environment (including interpersonal factors and the immediate living environment); the broader social context (including structural and cultural factors).

Traditional cultures often form the contexts for peoples sexual behaviour, for instance Sithole ([5] discusses cultural factors which contribute to the spread of HIV/AIDS in Southern Africa and singles out key cultural practices which act as contributory factors to AIDS to include male circumcision, female genital mutilation, early and compulsory marriage of girls, sexual abuse and rape of women and girls, cosmetic tattooing or administration of charms, widow inheritance and death cleansing. Other factors include breakdown of family patterns, gender relations, traditions, moral values and behavioural patterns caused by a shift from rural to urban environments. According to Sithole [5] the perception amongst many African communities is that sexual activity is related to social status and for males, an important expression of their masculinity. The view of sex is as an activity for fun and fame; if a man sleeps around, he is more popular. The culture in Swaziland supports the multiplicity of sexual partners for men. A man who engages in multiple sexual encounters is known as ingwanwa which is positive and widely accepted. The female equivalent ingwandla is a derogatory term. The upbringing of boys and young men encourages them to dominate at family, community and societal level, thus sex becomes a means and a symbol of domination and power over the other sex. The metaphor of a bull, symbolic of strength is usually associated with manliness: the perception of a man is always searching for mating partners along life's journey.

Inness [6] describes the South African culture as being generally male dominated, with women accorded a lower status than men. Men have been socialised to believe women are inferior and should be under their control; women are socialised to over-respect men and act submissively towards them. The unequal power relations between the sexes particularly when negotiating sexual encounters, increases the women's vulnerability to HIV-infection accelerating the epidemic.

Gender inequality in Africa continues to be a major obstacle for HIV prevention programmes. For example, a woman who is faithful to her husband cannot, in many African societies, refuse sexual advances from her high risk husband, without fear of physical harm, economic retaliation or social ostracism (Van Dyk [7]). Rape or seduction of teenage girls by rich older men continues at alarmingly high rates in African societies (Attawell, [8]). Findings from studies conducted on sexual behavior 
suggest that poor women may be particularly vulnerable to HIV-infection. This is evident in sustained high-risk sexual practices by women who are aware of HIV/AIDS transmission and prevention. Many women may abandon safe sexual practices in exchange for economic and financial security, despite knowing the risks of doing so. Poverty appears to play a prominent role in influencing sexual decision-making by limiting individuals' decision-making powers in sexual relationships (Department of Health et al. [9]; Fourie and Furter, [10]; Fourie and Furter, [11]; Attawell, [8].). The resultant consequence is a high risk population. Widow inheritance, ukungena-in Ndebele/ Zulu or kugara Nhaka in Shona is widely practiced in many parts of Southern Africa, especially in a country such as Swaziland. The practice entails the younger brother or relative of the deceased husband "remarrying" the surviving woman and if not observed, the spirit of the dead man will visit the living to make demands. The reasons behind the practice are: to prevent the widow from committing adultery; to keep the wealth of the deceased within the family and in some societies, to appease the spirit of the deceased and prevent it from visiting the living and exacting punishment. The belief is that the spirit of the dead resides among the living overseeing all their daily activities (Van Dyk, [7]). Among some communities within the Southern African region and among minority groups in Zimbabwe, widow inheritance follows a practice that widely exposes both the widow and the deceased's brother to HIV/AIDS. Death in many African societies is a bad omen and in many cases, families are cleansed following the death of a family member. Different activities are performed to cleanse the family of this bad omen; it could be a simple ritual by traditional healers and other activities of a sexual nature. According to this practice, it is expected that a woman undergoes sexual cleansing. She is compelled to sleep with a stranger, in some cases someone with mental illness, in order to transfer this bad omen to the person that society considers useless (Sithole, [5]). Common belief is that a person who is normal and productive cannot take the weight of a bad omen. The dangerous part of this ritual cleansing is that the person whom the widow sleeps with may be infected and in turn, infecting the widow, who will then pass it on to her inheritor. Central to the whole practice is that the family tends to force the wife to accept inheritance or the brother to inherit the deceased brother's wife. Another unfortunate aspect of this cultural belief is the non publication of the cause of death even if it is HIV and AIDS.

Many African cultures consider it taboo for men to have sex with their wives during menstruation and late pregnancy. At such times, many men do not abstain or seek alternative means of release, such as non-penetra- tive sex, but seek sex with other women. It is not uncommon for a man to contract HIV through casual sex while his wife is pregnant. He then transmits it to his wife after childbirth, and she passes it to the baby through breastfeeding being during the initial stages of HIV infection. Men who have been ill for lengthy periods may be advised by traditional healers to sleep with a virgin girl (Sithole, [5]), a dangerous urban myth making the rounds in South Africa's urban rural settlements known as "townships". It has led a number of HIV-positive men raping little girls and babies. In Tswana culture, the interpretation of a long is as the result of a spell or a curse rather than anything to do with sexual behaviour. Traditionally, prolonged illness can be attributed to a number of factors such as sleeping with a woman during her menstrual period, having intercourse with a widow or a woman who has had a miscarriage (Akinade, [12]). Pervasive polygamy is a practice most common in certain areas of South Africa, Zimbabwe and Swaziland. In this practice, parents give their young daughters to older men who are already married with several wives, for economic benefits. In most cases there is consultation with the innocent girl and early marriages like this expose the young girls to high risks of contracting HIV and AIDS. There also exists a cultural practice known as "dry sex" in many parts of the African continent where, women, mainly prostitutes, insert substances into their vagina prior to intercourse to prevent wetness of the vagina. The belief is this produces a hot tight and dry environment which men find pleasurable. There are also cultures where virginity is highly regarded as criteria for respectability and subsequent marriage. Many young women in these cultures resort to anal sex, a practice reported in South Africa, Malawi and Zambia (Sithole, [5]), to keep their lovers from looking elsewhere for sex and maintain their respect which society accords to virgins. All these expose women to high risks of contracting HIV and AIDS. Van Dy, (2003) believes that unless salient aspects of the African cultural practices such as the ones mentioned above are taken into account by AIDS educators, the battle against HIV/AIDS will continue to be an uphill battle.

Many theatre interventions have been dominated by top down communication model in which groups, armed with pre-scripted, pre-rehearsed plays, without any idea of the cultural and economic dynamics of their target audience into communities hoping to achieve some measures of success in HIV/AIDS intervention. The audience in this case become passive recipients of "superior knowledge" by these groups. Eyoh [13] refers to it as "turning the audience into guinea pigs for our experiments”. 


\section{Context for the Study}

\section{Research Tours with the Centre for HIV/AIDS Management Stellenbosch University}

In April, 2011, I travelled with The Centre for HIV/AIDS Management theatre group on their HIV and AIDS campaign tours of various schools in the Boland area as a non-participant observer. My intention was to observe their dramatic performances to the learners in these schools and find out how much of the cultural as well as socio-economic dynamics of this target audience was encapsulated in the play.

The group performed to mainly learners in high schools. The drama performance piece, entitled Lucky, the Hero! traces the journey of a young man, Lucky, who becomes aware of his risky behavior through information given on a radio programme. Lucky has taken the brave step to get tested after realizing his risks by having sexual contact without using a condom. After revealing his status to his best friend who gossips the information to the whole community, he is ostracized stigmatized by all. From facts given to him as an anonymous caller on the radio station, he gains considerable self assurance and confidence that his life still has great value and a positive and bright future. He disguises himself as "Captain Aids Fighter" to inform the community about HIV and AIDS and change their thinking about the disease as well as on how they treat people with the disease.

To ascertain whether or Centre for HIV/AIDS Management theatre group's performances have improved the learners' awareness of issues relating to HIV and AIDS, I undertook a post-performance evaluation. I undertook a focus group session with the pupils (the target audience) with their life skills teachers as moderators. I also held individual interviews with the Life skills teachers in the schools concerned as well as the performer-educators of the group.

The expected objectives of this survey were to:

- Ascertain the level of awareness-raising of the group's performances in the schools where it was designated to perform and raise awareness on HIV and AIDS.

- Assess how much of the cultural norms and values of the community was contained in the play performed to the target audience and how this impacted on the learners reception of the message of HIV/AIDS encapsulated in the play.

- Set a baseline for future research regarding HIV and AIDS awareness campaigns by theatre groups in South Africa.

\section{Methodology}

This study utilizes qualitative research methodology to gain insight into the efficacy or otherwise of models and theories used by theatre groups in HIV/AIDS campaigns in South Africa. My study aims to gather an in-depth understanding of human behavior around HIV/AIDS and the reasons that govern such behavior. It interrogates the place of culture in sexual behaviour. The methodology applied in this study aims to analyse detailed descriptions of situations, events interaction and observed behaviour; quotations from people about their experiences, programme receptivity, attitudes, beliefs and thoughts.

\subsection{Research Design}

This is a Case Study of Centre for HIV/AIDS Management Theatre group with specific emphasis on the Western Cape province of South Africa.

\section{Data Collection}

Data collection was done using focus group interviews with learners in primary schools around Western Cape Province, individual interviews with the Life skills teachers of the respective schools. In addition to these I applied the participant observation strategy in which I operated as non-participant observer.

\subsection{Population of Study}

The research is based on

1) The activities of a prominent theatre group from the Centre for HIV/AIDS Management which is involved in HIV/AIDS campaign around the country.

2) Target Audience: The above named theatre group guided my selection of schools. As is usually the procedure, the group is usually invited by the schools upon application, to perform HIV/AIDS plays to their learners. 3 high schools based in the Boland district of the Western Cape invited the theatre group to perform. Using probability Sampling, I selected a total of 6 learners from each school bring the total number of learners to 18 learners. Three Life skills teachers one from each school were also selected.

\section{The Western Cape}

Our tour of the Western Cape took us to three high schools in the Boland area. Some of the schools are traditionally coloured schools while some were mixed in terms of race and ethnicity. The focus group sessions took place with 18 learners, while the individual interviews had 3 life-skills teachers, and 3 performers.

\section{Findings of the Study}

Table 1 represents the themes and categories selected from the focus group interviews as well as interviews 
Table 1. Themes and categories generated from focus group interviews.

\begin{tabular}{|c|c|}
\hline Themes & Categories \\
\hline $\begin{array}{l}\text { Top down } \\
\text { communication }\end{array}$ & $\begin{array}{l}\text { - Passive audience } \\
\text { - Non involvement of target communities }\end{array}$ \\
\hline $\begin{array}{l}\text { Failed to address } \\
\text { key realities in } \\
\text { communities }\end{array}$ & $\begin{array}{l}\text { - Too much focus on coloured communities } \\
\text { - Violence } \\
\text { - Single motherhood } \\
\text { - Drugs } \\
\text { - Alcohol abuse } \\
\text { - Teenage problem } \\
\text { - Sexual immorality }\end{array}$ \\
\hline $\begin{array}{l}\text { Non-representation } \\
\text { of culture }\end{array}$ & $\begin{array}{l}\text { - Lack of cultural diversity } \\
\text { - Language } \\
\text { - Dressing } \\
\text { - Punishment }\end{array}$ \\
\hline Structural issues & - Poverty \\
\hline $\begin{array}{l}\text { Non realistic } \\
\text { presentation }\end{array}$ & $\begin{array}{l}\text { - Age of performers } \\
\text { - Performers non diversity }\end{array}$ \\
\hline
\end{tabular}

with life skills teachers and performer educators.

\subsection{Top down Communication}

\section{Passive Audience}

The Centre for HIV/AIDS Management theatre group applied top-down communication strategy and did not represent a full participatory strategy. The audience were reduced to a position of passivity in their reception of the message which was the sole creation of the theatre group. This is why salient aspects of target group's diversity mentioned by respondents were ignored.

\subsection{Failure to Address Key Realities}

Many of the respondents believe that the play did not address key realities in their lives. They felt that too much emphasis was paid to HIV/AIDS without addressing factors that contribute to AIDS in their communities. They felt that there were rather extreme sexual behaviours in their communities that contribute to AIDS that were not highlighted in the play:

Many of our men have multiple partners. They are $a b-$ sent father figures in this community. The play did not show this (Respondent 4).

Play addressed few problems in our community and left out major ones (Respondent 5).

Play did not address extreme immoral sexual practices in the coloured community such as a man fathering children with both mother and daughter (Respondent 4).

Step fathers in this community sleep with their stepdaughters when the mother is at work. This was not in the play.
We have a lot of problems with gangsterism and rape in this place. I didn't see this in the play. It was just dancing and having fun (Respondent 2).

Without finding out what the key issues are within a community theatre is bound to fall into the trap of "domesticating" its target group. Parker [14] contends that "much of HIV/AIDS communication tend to be directed at people without reflecting their unique perspectives".

\subsection{Non Representation of Culture and Cultural Diversity}

While the respondents from the mainly coloured schools felt the play represented the coloured community to a certain extent, respondents from the more diverse schools felt the play focused too much on the coloured community to the exclusion of the other cultural groups. As one of the respondents argued:

Not all cultures in this community were represented in this play (Respondent 6 ).

Some respondents went further to argue that even the cast members should be representative of the diversity:

The cast members do not represent the diversity of cultures in this place (Respondent 5).

These respondents felt left out because the dynamics of their culture did not form part of the performance. According to Gould [15], it is impossible to negotiate any level of human change without confronting culture" of the target audience. Somma and Bodiang [16] agree by stating that "conventional health campaigns have failed to elicit behavior change because they are performed outside the social and cultural context of target audience. In this case people may hear the message but fail to internalise it because the message is delivered outside of the realms of their culture".

\subsubsection{Language}

The respondents also pointed out that not enough of their cultural norms and values were reflected in the play. This hampered their understanding of the play and its message. Key aspects such as language and dressing were not reflected in the play:

Language was a problem. I don't speak Afrikaans so I don't understand what was going on. There were so many black children in the audience who did not understand what was going on. They should have at least used English (Respondent 1).

I am Xhosa and don't understand Afrikaans language. I didn't understand the message in the play (Respondent 4).

I am not comfortable with the sexy dances on stage, My culture does not support such open display of sexual desire. I am Xhosa (Respondent 2). 
In the fight against HIV/AIDS in South Africa, language has been identified as one of the explicit or surface manifestation of culture needed to accomplish a culturally sensitive intervention. Mkhulisi [17] believes it is through a language that you empower a person by giving him a right to experience his language rights”. Unfortunately this was not the case with the respondents and thus the HIV/AIDS message was lost on a sizeable number of audience members in this case.

\subsubsection{Punishment and Reward}

A number of respondents brought up the issue punishment and reward, an important aspect of African worldview. In traditional Africa people who violate certain laid down conventions usually receive punishment for their errors. With that in mind, respondents were surprised that in the play not enough punishment was meted out to characters whose sexual behavior could be classified as careless:

I feel the play was too soft on the consequences of sexual behaviour. People like to see offenders punished:

The concept of punishment for transgression comes from the traditional African society where morality was held as top priority. According to Ogden and Nyblade [18] "in a number of African societies, specific illness or sets of symptoms are associated with having broken one or more social prohibitions". The belief in punishment for violation is so strong, Africans have come to believe that people suffering with AIDS are being punished for their sins. The respondents want this to be reflected in the play. In the play the character who finds out that he is HIV-positive is portrayed as having transcended the disease when he becomes a campaigner for other HIVpositive people. But respondents want a more realistic presentation where the character finds out he is positive and go through a process of suffering without any reprieve which represents punishment. Respondents believe that the more the emphasis placed on punishment, the more the audience will take the message seriously.

\subsection{Structural Factors}

\section{Poverty}

Another area that the respondents picked up is the structural factors which the play did not address. Some respondents believe that poverty which is a major problem in their community was not reflected in the play. All they saw was happy dancing farm workers:

There was too much emphasis on sex as a cause of HIV. I feel that the play did not teach me what I didn't know already (Respondent 6).

The play did not address the question of poverty which is high in our community (Respondent 5).
Research has established the relationship between poverty and HIV/AIDS (Booysen \& Summerton [19]). According to Attawell [8], young girls engage in sexual intercourse at an early for material gain or favours from sexual partners. When people have to struggle for economic survival, their ability to make rational sexual decision is limited (Dutta-Bergman [20]).

In conclusion, the data clearly suggests that the groups' performances did not achieve the level of understanding of its message as originally desired. The use of top down communication, non involvement of target audiences in the design of intervention instrument has created a situation where the groups' message is weakened by its inability to address cultural issues that operates at the heart of its target audience. The group's lack of appreciation of the structural dynamics of its community has also worked to weaken its effectiveness as behavior change agent.

\section{Conclusions}

Any intervention that seeks to change behavior must be rooted in the cultural norms of target audience. Anything to the contrary runs the risk of failing. Individual cultures around the world have their specific belief systems that govern their conceptualisation of disease epistemology. The results of the fieldwork in this study have shown that people are uncomfortable when confronted with a health message located outside the realms of their culture.

Based on the responses derived from the focus group sessions as well as individual interviews conducted in this study, it is clear that not enough of the cultural norms and values of the target community was encapsulated in the design of the play performed by the group. The views of the respondents captured during the focus group sessions and individual interviews indicate that the play did not totally address salient aspects of their cultural beliefs. Added to this is the fact that the play did not represent some the realities of life in each given community. People are entangled in different cultural webs and to be affected by a message, they have to hear it in a way that has cultural significance for them and which connects with their life experiences (Albright [21]). There is no doubt that theatre has made an impression as far as HIV/AIDS campaign is concerned. But to achieve greater success, theatre needs to re-examine its methodology to reflect the concerns of the target audience regarding cultural norms and values. It has already been pointed out that there was no participatory approach and therefore the design of the intervention approach failed to incorporate any input from the target audience. Any health intervention programme which does not take the question of cultural norms of target communities very 
seriously runs the risk of underachieving as far effecting behavior change is concerned. According to Gould [15], it is impossible to negotiate any level of human change without confronting culture. A cultural approach sets out to systematically engage with what Gorringe [22] calls "web of significance" a term that describes the totality of the intricacies of culture. It stands to reason that a worldwide health crisis such as HIV/AIDS which is deeply rooted in culture requires a cultural solution.

\section{REFERENCES}

[1] H. Hoeken and P. Swanepoel, "Adapting Health Communication to Cultural Needs: Optimizing Documents in South African Health Communication on HIV and AIDS," John Benjamins Publishing Company, Amsterdam/Philadelphia, 2009.

[2] C. Campbell, "Letting Them Die: Why HIV/AIDS Intervention Programmes Fail,” Indiana University Press, Bloomington \& Indianapolis, 2003.

[3] L. Eaton, A. J. Flisher and L. E. Aaro, "Unsafe Sexual Behavior in South African Youth," Social Science \& Medicine, Vol. 56, No. 4, 2003, pp. 149-165. doi:10.1016/S0277-9536(02)00017-5

[4] R. Perloff, "Persuading People to Have Safer Sex: An Application of Social Sciences to the AIDS Crisis," Lawrence Erlbaum Associates Inc., Mahwah, 2000.

[5] J. Sithole, "Cultural Factors in the Spread and Management of HIV/AIDS in Southern Africa," In: E. Biakolo, J. Mathangwane and D. Odallo, Eds., The Discourse of HIVIAIDS in Africa, University of Botswana, Gaborone, 2003, pp. 142-145.

[6] R. O. Inness, “Sociocultural Aspects of AIDS,” 2006. http://www.health.com/medical/conditioncetres/777-792814-1762asp

[7] A. C. van Dyk, "Traditional African Beliefs and Customs: Implications for AIDS Education and Prevention in Africa," South African Journal of Psychology, Vol. 31, No. 2, 2003, pp. 1-9.

[8] K. Attawell, "HIV/AIDS Knowledge, Attitudes, Beliefs and Behaviours in South Africa: Literature Review,” National Directorate HIV/AIDS and STD, Pretoria, 1998.

[9] Department of Health, Medical Research Council \& Macro International, "The South African Demographic and Health Survey 1998,” Department of Health, Pretoria, 1999.

[10] A. Fourie and A. Furter, "Sexually Transmitted Infections and HIV/AIDS: An Investigation into Knowledge Attitudes, Practice and Beliefs of the Botshabelo Community," Centre for Health Systems Research \& Develop- ment, Bloemfontein, 1998.

[11] A. Fourie and A. Furter, "Sexually Transmitted Infections and HIV/AIDS: An Investigation into Knowledge, Attitudes, Practices and Beliefs among School Going Teenagers in Thabanchu," Centre for Health Systems Research \& Development, Bloemfontein, 1998.

[12] A. Akinade, "Cultural Practices That Influence the Spread of HIV and AIDS in Botswana," In: E. Biakolo, J. Mathangwane and D. Odallo, Eds., The Discourse of HIVIAIDS in Africa, University of Botswana, Gaborone, 2003, pp. 112-117.

[13] H. N. Eyoh, "Hammocks to Bridges: An Experience in Theatre for Development,” BET and Company, Yaounde, 1986.

[14] W. Parker, L. Dalrymple and E. Durden, "Communicating Beyond AIDS Awareness: A Manual for South Africa," Beyond Awareness Consortium, Johannesburg, 1998.

[15] H. Gould, "What's Culture Got to Do with HIV and AIDS? Why the Global Strategy for HIV and AIDS Needs to Adopt a Cultural Approach 2007,” (Online) Accessed on 21 July 2009.

http://www.healthlink.org.uk/PDFs/Findings7_hiv_cultur e.pdf

[16] D. B. Somma and K. C. Bodiang, “The cultural approach to HIV/AIDS prevention,” Swiss Agency for Development and Cooperation/Swiss Centre for International Health, Swiss Tropical Institute, Geneva, 2004.

[17] N. Mkhulisi, “The Role of Language Departments at Tertiary Institutions in Language Development,” The Workshop with Tertiary Institutions, Kwa Zulu Natal, 1999.

[18] J. Ogden and L. Nyblade, "Common at Its Core: HIVRelated Stigma across Contexts” International Centre for Research on Women, Washington DC, 2005.

[19] F. R. Booysen and J. Summerton, "HIV/AIDS, Poverty and Inequality: Evidence from the South African Demographic and Health Survey,” In: E. Biakolo, J. Mathangwane, D. Odallo, Eds., The Discourse of HIV/AIDS in Africa Department of English, University of Botswana, Gaborone, 2003, pp. 154-163.

[20] M. J. Dutta-Bergman, "Theory and Practice in Health Communication Campaign: A Critical Interrogation," Health Communication, Vol. 18, No. 2, 2003, pp. 103-122. doi:10.1207/s15327027hc1802_1

[21] K. Albright, "HIV/AIDS Information Seeking and Healthcare Communication in Sub-Saharan Africa," 73rd IFLA General Conference and Council, Durban, 19-23 August 2007, pp. 1-13.

[22] T. Gorringe, "Furthering Humanity: A Theology of Culture,” Ashgate Publishing Ltd., Aldershot, 2004. 